e-journal Keperawatan (e-Kp) Volume 7 Nomor 1, Februari 2019

\title{
HUBUNGAN BEBAN KERJA FISIK DAN MENTAL PERAWAT DENGAN PENERAPAN PATIENT SAFETY DI IGD DAN ICU RSU GMIM PANCARAN KASIH MANADO
}

\author{
Desiana Yudi \\ Jon W. Tangka \\ Ferdinand Wowiling
Program Studi Ilmu Keperawatan Fakultas Kedokteran
Universitas Sam Ratulangi Manado
Email : desiyudi16@gmail.com

\begin{abstract}
Patient safety is an important thing that must be considered by nurses in providing nursing care. Excessive physical and mental workload can affect the quality of health services provided. The purpose of the study was to determine the relationship between physical and mental workload of nurses with the application of patient safety. Method uses a correlation analytic research design with a cross sectional approach. The sample of this study used a total population of 30 nurses working at the emergerncy unit and ICU GMIM Pancaran Kasih HospitalManado. Results of the study used the chi square test at a significance level of 95\%, significant for physical workload with the application of patient safety ( $p$ value $0.023 ; \alpha 0.05$ ) and not significant for mental workload with the application of patient safety ( $p$ value $0.089 ; \alpha$ 0.05). Conclusion, nurse's physical workload is significantly related to the application of patient safety and the nurse's mental workload is not significantly related to the implementation of patient safety in the emergency unit and ICU RSU GMIM Pancaran Kasih Manado.
\end{abstract}

Keywords: physical workload, mental workload, patient safety.

Abstrak : Patient safety merupakan hal penting yang harus diperhatikan oleh perawat dalam memberikan asuhan keperawatan. Beban kerja fisik dan mental yang berlebihan dapat mempengaruhi mutu pelayanan kesehatan yang diberikan. Tujuan penelitian untuk mengetahui hubungan beban kerja fisik dan mental perawat dengan penerapan patient safety. Metode penelitian ini menggunakan desain penelitian analitik korelasi dengan pendekatan cross sectional. Sampel penelitian ini menggunakan total populasi yaitu seluruh perawat yang bekerja di IGD dan ICU RSU GMIM Pancaran Kasih Manado sebanyak 30 responden. Hasil penelitian dengan menggunakan uji chi square pada tingkat kemaknaan 95\%, signifikan untuk beban kerja fisik dengan penerapan patient safety (nilai p 0,$023 ; \alpha 0,05$ ) dan tidak signifikan untuk beban kerja mental dengan penerapan patient safety (nilai $p 0,089 ; \alpha$ 0,05). Kesimpulan, beban kerja fisik perawat berhubungan secara bermakna dengan penerapan patient safety dan beban kerja mental perawat tidak berhubungan secara bermakna dengan penerapan patient safety di IGD dan ICU RSU GMIM Pancaran Kasih Manado.

Kata Kunci : beban kerja fisik, beban kerja mental, patient safety.

\section{PENDAHULUAN}

Negara-negara anggota WHO tahun 2002 telah menyetujui Resolusi Dewan Kesehatan Dunia tentang keselamatan pasien sebagai pengakuan atas kebutuhan untuk mengurangi cedera pada pasien dan kesulitan pada keluarga pasien akibat dari pelayanan medis yang tidak memadai. Resolusi ini juga menekankan bahwa keselamatan pasien penting untuk meminimalisir biaya yang timbul akibat perawatan yang berulang dan biaya penanganan infeksi yang terjadi akibat pelayanan medis. Beberapa hal dapat 
menyebabkan cedera pada pasien seperti kesalahan dalam memeriksa identitas medis pasien, resep antibiotik yang diberikan tidak sesuai dengan kondisi pasien dan kurangnya komunikasi yang efektif antar penyedia layanan kesehatan (WHO, 2011).

Perawat sebagai profesi memiliki peran yang cukup besar dalam menjaga keselamatan pasien. Oleh karena itu perawat harus mampu memastikan bahwa pelayanan keperawatan yang diberikan mengedepankan keselamatan melalui asuhan keperawatan yang diberikan kepada pasien juga memiliki kesadaran akan pentingnya mengenali potensi bahaya yang ada di lingkungan pasien untuk mencegah terjadinya cedera (Kamil,2010). Menurut penelitian yang dilakukan oleh Sukmaretnawati tahun 2014 pada 19 responden hasilnya yaitu $21,1 \%$ responden tidak menggunakan minimal dua sistem identifikasi pasien. Identifikasi terkadang masih menggunakan nama dan sistem tempat tidur pasien. Hal ini disebabkan identifikasi dengan sistem tempat tidur pasien lebih cepat tetapi dapat mengakibatkan risiko tinggi terjadinya kesalahan, $42,1 \%$ perawat memberikan obat kepada pasien tanpa melihat kemiripan dari nama maupun jenis dari obat tersebut.

Instalasi Gawat Darurat (IGD) merupakan unit operasional rumah sakit yang penting karena memberikan pelayanan kepada pasien serta diperlukan tindakan yang cepat dan tepat dalam menangani pasien sehingga perawat yang bertugas di IGD memerlukan kemampuan berpikir kritis dan kemampuan fisik yang terlatih (Gunawati, 2013). Kondisi pasien kritis di ruang IGD dan ICU dilengkapi dengan berbagai fasilitas yang memerlukan keterampilan khusus seperti monitor jantung, respirator dan suasana kerja yang tenang memberikan kesan serius yang dapat memengaruhi mental perawat, serta menuntut keterampilan khusus untuk dapat melaksanakan pekerjaan di IGD dan ICU (Susanto, Bayhakki, \& Arneliwati,2015).
Menurut penelitian Kasmarani tahun 2012 tentang pengaruh beban kerja fisik dan mental terhadap stres kerja pada perawat di IGD RSUD Cianjur diketahui hasil bahwa kondisi beban kerja mental tinggi pada perawat IGD RSUD Cianjur sebesar $70,1 \%$ yang meliputi adanya variasikondisi pasien dan jenis penyakit, tuntutan waktu tiap tindakan terhadap pasien serta harus menghadapi keluarga pasien.Penelitian yang dilakukan oleh Susanto et al tahun 2015 mengenai hubungan persepsi beban kerja dengan stress kerja pada perawat IGD dan ICU Eka Hospital Pekanbaru pada 46 perawat terbukti bahwa sebanyak $60,9 \%$ perawat memiliki persepsi beban kerja berat dan $39,1 \%$ perawat dengan persepsi beban kerja ringan. Beban kerja perawat di rumah sakit meliputi beban kerja fisik maupun mental. Beban kerja fisik seperti mengangkat pasien, memasang infus, melakukan observasi tanda-tanda vital, memasang oksigen, dan lain-lain. Sedangkan beban kerja yang bersifat mental berupa kompleksitas pekerjaan, mempersiapkan mental dan rohani pasien dan keluarga terutama yang akan menjalankan operasi atau dalam keadaan kritis, bekerja dalam keterampilan khusus dalam merawat pasien, serta harus menjalin komunikasi yang baik dengan pasien dan keluarga.Penelitian yang dilakukan oleh Haryanto dan Rosa tahun 2016 mengenai pengaruh beban kerja dan kelelahan perawat terhadap perawatan infus di RSUD Sukoharjo terlihat bahwa beban kerja perawat mempengaruhi perawatan infus. Beban kerja yang berlebihan akan menimbulkan kelelahan baik fisik maupun mental yang mengakibatkan kurangnya konsentrasi pada pekerjaan sehingga berisiko melakukan kesalahan atau lupa untuk melakukan hal yang seharusnya dilakukan. Jika pemasangan dan perawatan infus tidak dilakukan sesuai prosedur yang benar maka dapat berisiko terjadinya infeksi yang diakibatkan oleh pelayanan kesehatan. 
Survei awal yang diambil pada tanggal dua dan tiga Oktober 2018 di ruangan ICU dan IGD RSU GMIM Pancaran Kasih Manado melalui wawancara dengan kepala ruangan ICU didapatkan bahwa perawat pelaksana ICU berjumlah delapan orang dengan rata-rata pasien per bulan sebanyak 15 orang. Perawat ICU mengeluh sering kelelahan dan mengalami stres dalam merawat pasien tidak sadar yang menuntut konsentrasi dan kemampuan berpikir kritis dalam memonitoring kondisi pasien yang dapat mengalami perubahan secara mendadak. Hasil observasi di ICU terlihat bahwa kegiatan-kegiatan yang dilakukan perawat ialah mengangkat pasien, mengatur posisi pasien, melakukan pemberian makanan, pemberian obat, mengobservasi kondisi pasien tiap jam,dan lain-lain serta ketika pasien datangperawat tidak mencuci tangan sebelum menangani pasien baru.

Hasil wawancara dengan kepala ruangan IGD diketahui bahwajumlah perawat pelaksana sebanyak 25 orang dan jumlah kunjungan pasien per hari 50-60 pasien dengan jenis penyakit dan tingkat kegawatan yang berbeda-beda. Perawat mengeluh banyak hal yang harus dikerjakan secara cepat dan tepat sehingga sering mengalami kelelahan. Hasil observasi di IGD didapatkan bahwa kegiatan-kegiatan yang dilakukan oleh perawat yaitu membersihkan ruangan, memasang infus, mengambil spesimen darah, melakukan observasi TTV, melakukan RJP (Resusitasi Jantung Paru), menulis dokumentasi tiap tindakan, menghadapi keluarga pasien yang panik, mengambil berkas-berkas dokumentasi, membersihkan ruangan dan lain-lain serta masih ada dua bed yang tidak menggunakan side rail, sebelum melakukan tindakan kepada pasien tidak mencuci tangan dan tidak menggunakan handscoon saat pengambilan spesimen darah. Semua perawat IGD dan ICU telah mengikuti pelatihan patient safety. Rumah sakit ini tergolong dalam rumah sakit tipe $\mathrm{C}$ yang telah terakreditasi. Berdasarkan fenomena diatas dan diketahui belum ada yang pernah meneliti mengenai judul ini maka peneliti tertarik untuk meneliti tentang hubungan beban kerja fisik dan mental perawat dengan penerapan patient safety di IGD dan ICU RSU GMIM Pancaran Kasih Manado.

\section{METODE PENELITIAN}

Jenis penelitian ini analitik korelasi dengan pendekatan cross sectional, yaitu variabel sebab atau risiko dan akibat atau kasus yang terjadi pada objek penelitian diukur dan dikumpulkan secara simultan, sesaat atau satu kali saja dalam satu kali waktu (dalam waktu yang bersamaan), dan tidak ada follow up (Setiadi, 2013). Penelitian ini telah dilakukan di ruangan IGD dan ICU RSU GMIM Pancaran Kasih Manado.Penelitian ini telah dilakukan pada bulan Oktober-Desember 2018. Dalam penelitian ini yang menjadi populasi adalah perawat pelaksana di IGD dan ICU RSU GMIM Pancaran Kasih Manado berjumlah 30 orang. Sampel dalam penelitian ini meliputi subjek yang memenuhi kriteria inklusi.

Penelitian ini menggunakan total populasi. Instrumen dalam penelitian ini menggunakan kuesioner beban kerja fisik perawat yang telah digunakan pada penelitian sebelumnya oleh Kambuaya tahun 2013 yang terdiri dari 29 pernyataan, kuesioner beban kerja mental dengan metode NASA-Task Load Indexyang telah digunakan pada penelitian sebelumnya oleh Gunawati tahun 2013 yang terdiri dari enam skala faktor yakni Kebutuhan Mental (KM), Kebutuhan Fisik (KF), Kebutuhan Waktu (KW), Usaha (U), Performansi (P) dan Frustasi (F) serta lembar observasi penerapan patient safety. Pengolahan data melalui tahap editing, coding, cleaning, dan processing. Data dianalisis melalui analisis univariat dan biavariat dengan menggunakan uji Chi Square dengan tingkat kemaknaan 95\% $(\alpha=0,05)$ untuk melihat hubungan antara masing-masing variabel independen dengan variabel dependen. 
Etika dalam penelitian ini yaitu memberikan lembar persetujuan (inform consent) kepada responden agar subjek penelitian mengetahui maksud dan tujuan peneliti, tidak mencantumkan nama responden namun menggunakan hanya inisial (anonymity), dan menghormati privasi dan menjaga kerahasiaan responden (confidentiality).

\section{HASIL dan PEMBAHASAN \\ Karakteristik Responden}

Tabel 1. Distribusi Frekuensi Responden Menurut Jenis Kelamin

\begin{tabular}{ccc}
\hline Jenis Kelamin & n & \% \\
\hline Laki-laki & 8 & 26,7 \\
Perempuan & 22 & 73,3 \\
\hline Total & 30 & 100 \\
\hline
\end{tabular}

Sumber : Data Primer 2018

Distribusi frekuensi berdasarkan jenis kelamin pada tabel 1. menunjukkan bahwa dari 30 responden, terbanyak jenis kelamin perempuan dengan jumlah 22 perawat (73,3\%). Hasil penelitian sebelumnya yang dilakukan oleh Manorek tahun 2018 tentang faktor-faktor yang mempengaruhi penerapan sasaran keselamatan pasien didapatkan bahwa kebanyakan responden berjenis kelamin perempuan dengan persentase $84,7 \%$. Secara psikologi, perempuan memiliki sifat atau naluri keibuan yang dibutuhkan dalam melayani, sehingga diharapkan sifat perawat perempuan lebih sabar dan perhatian dalam memberikan pelayanan

Tabel 2. Distribusi Frekuensi Responden Menurut Usia

\begin{tabular}{ccc}
\hline Usia & n & \% \\
\hline$<24$ tahun & 2 & 6,7 \\
$24-48$ tahun & 27 & 90 \\
$>48$ tahun & 1 & 3,3 \\
\hline Total & 30 & 100
\end{tabular}

Sumber : Data Primer, 2018

Distribusi frekuensi berdasarkan usia pada tabel 2. menunjukkan bahwa dari 30 responden, terbanyak responden dengan usia rentang 24 sampai 48 tahun sebanyak
27 perawat (90\%). Menurut Kumbadewi, 2016, usia produktif seorang pekerja berada dalam rentang 15 sampai 65 tahun sehingga dapat terlihat responden dalam penelitian ini tergolong usia produktif. Usia seseorang mempengaruhi tingkat produktivitasnya, semakin meningkat usia pekerja maka semakin tinggi juga tingkat produktivitasnya dan jika usia pekerja memasuki lanjut usia maka produktivitasnya menurun karena dipengaruhi oleh beberapa faktor seperti fisik dan status kesehatannya

Tabel 3. Distribusi Frekuensi Responden Menurut Lama Bekerja

\begin{tabular}{ccc}
\hline Lama Bekerja & n & \% \\
\hline$<10$ bulan & 4 & 13,3 \\
$10-20$ bulan & 6 & 20 \\
$>20$ bulan & 20 & 66,7 \\
\hline Total & 30 & 100 \\
\hline
\end{tabular}

Sumber : Data Primer, 2018

Distribusi frekuensi berdasarkan lama bekerja pada tabel 3 menunjukkan bahwa dari 30 responden, lama bekerja lebih dari 20 bulan paling banyak dengan jumlah 20 perawat (66,7\%). Hasil penelitian Aprilia tahun 2011 tentang faktor-faktor yang mempengaruhi perawat dalam penerapan patient safety didapatkan bahwa kebanyakan responden memiliki lama bekerja lebih dari lima tahun sebanyak 48 perawat $(68,5 \%)$. Menurut Manorek tahun 2018, lama bekerja bisa mempengaruhi kinerja seseorang. Semakin lama seseorang bekerja maka semakin tinggi pula tingkat kedewasaannya dalam mengelola setiap masalah yang terjadi ditempat kerja.

Tabel 4. Distribusi Frekuensi Responden Menurut Pendidikan Terakhir

\begin{tabular}{ccc}
\hline $\begin{array}{c}\text { Pendidikan } \\
\text { Terakhir }\end{array}$ & n & \% \\
\hline D III & 22 & 73,3 \\
S1 & 2 & 6,7 \\
S1 Ners & 6 & 20 \\
\hline Total & 30 & 100 \\
\hline
\end{tabular}

Sumber : Data Primer 2018 
Distribusi frekuensi berdasarkan pendidikan terakhir pada tabel 4 . menunjukkan bahwa paling banyak responden memiliki pendidikan terakhir D III yaitu sebanyak 22 perawat $(73,3 \%)$. Penelitian yang dilakukan oleh Lombogia tahun 2016 di ruang akut IGD RSUP Prof. Dr. R. D. Kandou Manado tentang hubungan perilaku dengan kemampuan perawat dalam melaksanakan patient safety kebanyakan responden dengan pendidikan terakhir D III Keperawatan sebanyak 19 responden (61,3\%). Menurut Renoningsih tahun 2016, kemampuan seorang perawat dipengaruhi oleh tingkat pendidikannya. Pendidikan yang tinggi dapat meningkatkan kematangan intelektual seseorang sehingga pengetahuan yang dimiliki dapat dikembangkan dan diterapkan dalam pelayanan kesehatan yang diberikan kepada pasien.

Analisa Univariat

Tabel 5. Distribusi Frekuensi Responden Berdasarkan Beban Kerja Fisik

\begin{tabular}{lcc}
\hline \multicolumn{1}{c}{ Beban Kerja Fisik } & n & \% \\
\hline Sedang & 13 & 43,3 \\
Tinggi & 17 & 56,7 \\
\hline Total & 30 & 100 \\
\hline
\end{tabular}

Sumber : Data Primer 2018

Distribusi frekuensi berdasarkan variabel beban kerja fisik pada tabel 5 . menunjukkan bahwa kebanyakan responden memiliki beban kerja fisik tinggi yaitu 17 perawat (56,7\%). Hal ini sejalan dengan penelitian yang dilakukan oleh Haryanti tahun 2013 beban kerja perawat IGD dalam melakukan kegiatan fisik seperti mengantar pasien ke ruangan dan memasang kateter intravena tergolong tinggi yaitu sebanyak $93,3 \%$ dan beban kerja rendah diketahui ada 6\%. Hal ini bisa terjadi karena kurangnya tenaga khusus yang akan melakukan tindakan non keperawatan seperti mengurus kelengkapan administrasi pasien, membersihkan ruangan, dan lain-lain sehingga pelaksanaannya dilakukan oleh perawat ruangan.
Kegiatan yang sering dilakukan oleh perawat pelaksana di IGD dan ICU ialah serah terima pasien, mengangkat dan memindahkan pasien, mengantar pasien ke ruangan inap, memasang infus, mengobservasi keadaan pasien, memberikan obat kepada pasien, merawat luka pasien, sterilisasi alat kesehatan, mengambil spesimen darah, menghitung keseimbangan cairan, mengatur posisi pasien, dan lain-lain. Faktor-faktor seperti tidak seimbangnya jumlah perawat dengan pasien yang dilayani, tuntutan sebagai perawat IGD dan ICU yang harus melakukan kegiatannya secara cermat, cepat dan tepat, kurangnya kerja sama antar tim dapat mempengaruhi beban kerja yang berlebihan pada perawat.

Tabel 6. Distribusi Frekuensi Responden Berdasarkan Beban Kerja Mental

\begin{tabular}{ccc}
\hline Beban Kerja Mental & $\mathbf{n}$ & $\mathbf{\%}$ \\
\hline Sedang & 28 & 93,3 \\
Tinggi & 2 & 6,7 \\
\hline Total & 30 & 100 \\
\hline
\end{tabular}

Sumber : Data Primer, 2018

Distribusi frekuensi berdasarkan variabel beban kerja mental pada tabel 6 . menunjukkan bahwa paling banyak responden memiliki beban kerja sedang, sebanyak 28 perawat $(93,3 \%)$. Beban kerja mental yang dialami perawat IGD dan ICU bisa terjadi karena lingkungan kerja yang menuntut tingkat kewaspadaan yang tinggi dalam menangani pasien total care di ICU, datangnya pasien dengan variasi tingkat kegawatan dan jenis penyakit, harus menghadapi keluarga pasien yang cemas dengan anggota keluarganya yang sedang dirawat dan cenderung sering bertanya kepada perawat tentang kondisi anggota keluarganya, serta tuntutan harus secepatnya mengambil keputusan untuk melakukan tindakan pada pasien gawat darurat dan kritis agar tidak terjadi masalah kesehatan yang lebih serius. 
Tabel 7 Distribusi Frekuensi Responden Berdasarkan Penerapan Patient Safety

\begin{tabular}{ccc}
\hline $\begin{array}{c}\text { Penerapan Patient } \\
\text { Safety }\end{array}$ & n & \% \\
\hline Baik & 12 & 40 \\
Kurang & 18 & 60 \\
\hline Total & 30 & 100 \\
\hline
\end{tabular}

Sumber : Data Primer, 2018

Distribusi frekuensi berdasarkan variabel penerapan patient safety pada tabel 7 menunjukkan bahwa penerapan patient safety oleh responden paling banyak tergolong kurang sebanyak 18 perawat $(60 \%)$. Dari hasil observasi saat penelitian dilakukan terlihat bahwa dalam hal identifikasi pasien perawat sudah melakukannya namun belum dilakukan secara sempurna karena sistem identifikasi pasien seringkali hanya menggunakan sistem tempat tidur dan nama pasien yang terlihat mudah dilakukan tetapi berisiko menimbulkan kesalahan.

Perawat dalam menangani pasien perawat sudah melakukan tindakan pengurangan risiko infeksi dengan mencuci tangan sebelum dan sesudah kontak dengan pasien namun tidak dilakukan sesuai dengan prosedur yang berlaku. Faktor lain juga yang dapat mempengaruhi penerapan patient safety seperti lingkungan kerja yang tidak kondusif seperti tidak ada kerjasama, kejenuhan, kelelahan, dan beban kerja berlebihan dari perawat dapat menimbulkan risiko melakukan kesalahan.

\section{Analisa Bivariat}

Tabel 8. Analisis Hubungan Antara Beban Kerja Fisik dengan Penerapan Patient Safety

\begin{tabular}{|c|c|c|c|c|c|c|c|}
\hline \multirow{3}{*}{$\begin{array}{c}\text { Beban } \\
\text { kerja } \\
\text { fisik }\end{array}$} & \multicolumn{6}{|c|}{ Penerapan Patient safety } & \multirow{3}{*}{$\begin{array}{c}p \\
\text { value }\end{array}$} \\
\hline & \multicolumn{2}{|c|}{ Baik } & \multicolumn{2}{|c|}{ Kurang } & \multicolumn{2}{|c|}{ Total } & \\
\hline & $\mathbf{n}$ & $\%$ & $\mathbf{n}$ & $\%$ & $\mathbf{n}$ & $\%$ & \\
\hline Sedang & 5 & 16,6 & 8 & 26,7 & 13 & 43,3 & \\
\hline Tinggi & 7 & 23,4 & 10 & 33,3 & 17 & 56,7 & 0,023 \\
\hline Total & 12 & 40 & 18 & 60 & 30 & 100 & \\
\hline
\end{tabular}

Sumber : Data Primer, 2018
Analisis hubungan antara beban kerja fisik dengan penerapan patient safety pada tabel 8. menunjukkan bahwa dari 13 responden yang memiliki beban kerja fisik sedang, 5 perawat $(16,6 \%)$ dikategorikan baik dalam menerapkan patient safety dan 8 perawat $(36,7 \%)$ dikategorikan kurang dalam menerapkan patient safety. Sedangkan dari 17 responden yang memiliki beban kerja fisik tinggi, 7 perawat $(23,4 \%)$ dikategorikan baik dalam menerapkan patient safety dan 10 perawat $(33,3 \%)$ dikategorikan kurang dalam menerapkan patient safety.Hasil akhir dari analisis menggunakan uji Chi Square didapatkan nilai $p$ valuesebesar 0,023 yang berarti bahwa nilai $p$ value $(0,023)<$ nilai $\alpha$ $(0,05)$ sehingga dapat disimpulkan $\mathrm{Ha}$ gagal ditolak, yaitu ada hubungan antara beban kerja fisik perawat dengan penerapan patient safety di IGD dan ICU RSU GMIM Pancaran Kasih Manado. Semakin tinggi beban kerja fisik perawat maka berpengaruh pada penerapan patient safety yang kurang

Aktivitas kerja fisik yang melampaui kapasitas seorang perawat dapat menurunkan produktivitasnya dalam bekerja sehingga hal-hal yang harusnya dilakukan untuk menjaga keselamatan pasien sering dilakukan namun tidak sesuai dengan prosedur yang berlaku. Hal ini sejalan dengan penelitian yang dilakukan oleh Kambuaya tahun 2016 tentang hubungan beban kerja perawat dengan waktu tanggap pelayanan keperawatan di IGD, dimana terdapat hubungan antara kedua variabel tersebut. Hal ini dikarenakan banyaknya jumlah kunjungan pasien dan meningkatnya lama perawatan di IGD mengakibatkan perawat mengalami kelelahan sehingga berdampak buruk pada pelayanan yang diberikan yaitu keterlambatan dalam menangani pasien yang datang.

Penelitian ini bertentangan dengan penelitian yang dilakukan oleh Satria tahun 2013 dimana tidak terdapat hubungan antara beban kerja baik fisik maupun mental perawat dengan kinerja 
implementasi patient safety dikarenakan perawat-perawat yang ada terbiasa bekerja dengan beban kerja yang tinggi sehingga tetap dapat melaksanakan tugasnya dengan baik. Dalam pelaksanaan patient safety, keadaan fisik sangat berpengaruh dalam meningkatkan konsentrasi dalam bekerja sehingga tingkat kesalahan yang dilakukan dapat dicegah atau diminimalisir. Namun, ada beberapa faktor lain yang mempengaruhi yaitu adanya kerjasama yang baik dalam membangun kesadaran dari perawat. Kerjasama yang baik akan membuat pekerjaan tiap perawat tidak terasa lebih berat sehingga setiap pelayanan yang diberikan dapat efektif.

Tabel 9. Analisis Hubungan Antara Beban Kerja Mental Dengan Penerapan Patient Safety

\begin{tabular}{cccccccc}
\hline \multirow{2}{*}{$\begin{array}{c}\text { Beban } \\
\text { kerja } \\
\text { mental }\end{array}$} & \multicolumn{4}{c}{ Penerapan Patient safety } & \multicolumn{2}{c}{ Baik } & \multicolumn{2}{c}{ Kurang } & \multicolumn{2}{c}{ Total } & v \\
\cline { 2 - 7 } & $\mathbf{n}$ & $\%$ & $\mathbf{n}$ & $\%$ & $\mathbf{n}$ & $\%$ & \\
\hline Sedang & 11 & 36,7 & 17 & 56,7 & 28 & 93,4 & \\
Tinggi & 1 & 3,3 & 1 & 3,3 & 2 & 6,6 & 0,089 \\
\hline Total & 12 & 40 & 18 & 60 & 30 & 100 & \\
\hline
\end{tabular}

Sumber : Data Primer, 2018

Analisis hubungan antara beban kerja mental dengan penerapan patient safety pada tabel 9. menunjukkan bahwa dari 28 responden yang memiliki beban kerja mental sedang, 11 perawat $(36,7 \%)$ dikategorikan baik dalam menerapkan patient safety dan 17 perawat $(56,7 \%)$ dikategorikan kurang dalam menerapkan patient safety. Sedangkan 2 responden yang memiliki beban kerja mental tinggi juga dikategorikan kurang dalam menerapkan patient safety. Hasil akhir dari analisis menggunakan uji Chi Square didapatkan nilai $p$ valuesebesar 0,089 yang berarti bahwa nilai $p$ value $(0,089)>$ nilai $\alpha$ $(0,05)$ sehingga dapat disimpulkan $\mathrm{Ha}$ ditolak dan $\mathrm{HO}$ diterima, yaitu tidak ada hubungan antara beban kerja mental perawat dengan penerapan patient safety di IGD dan ICU RSU GMIM Pancaran Kasih Manado.
Sikap dan perilaku seorang perawat dapat mempengaruhi penerapan patient safety di rumah sakit. Kurangnya sikap perawat yang sabar, patuh dan bertanggung jawab akan menunjukkan kinerja yang kurang baik dari seorang perawat sehingga baik dalam keadaan lelah atau tidak, perawat tetap menunjukkan kinerja yang kurang baik. Hal ini didukung dengan penelitian yang dilakukan oleh Bawelle tahun 2013 yang menyatakan bahwa ada hubungan antara sikap perawat dengan pelaksanaan patient safety. Sikap perawat yang baik akan terwujud pada tanggung jawab atas seluruh pekerjaannya dengan segala risko yang akan dihadapi. Hal ini juga dapat disebabkan perawat memiliki faktor lain yang dapat mempengaruhi produktivitas dalam bekerja termasuk penerapan patient safety yaitu sikap perawat yang dewasa dalam menyelesaikan permasalahan yang terjadi dilingkungan kerja sehingga tidak menimbulkan stres yang berdampak pada pelayanan yang diberikan kepada pasien maupun keluarga pasien.

Penelitian ini juga didukung dengan penelitian yang dilakukan oleh Frichilia tahun 2016, menyatakan bahwa beban kerja berlebih akibat tuntutan tugas yang harus diselesaikan tidak selamanya mengganggu kinerjanya, namun bisa memacu seseorang untuk bekerja agar mencapai hasil yang optimal. Pekerjaan yang disenangi akan mencerminkan sikap positif pekerjanya sehingga meskipun pekerjaan tersebut menuntut kerja lebih namun pekerjanya tetap dapat melakukan yang terbaik. Hal ini juga dapat disebabkan perawat memiliki faktor lain yang dapat mempengaruhi produktivitas dalam bekerja termasuk penerapan patient safety yaitu sikap perawat yang dewasa dalam menyelesaikan permasalahan yang terjadi dilingkungan kerja sehingga tidak menimbulkan stres yang berdampak pada pelayanan yang diberikan kepada pasien maupun keluarga pasien. 


\section{SIMPULAN}

1. Beban kerja fisik perawat di IGD dan ICU RSU GMIM Pancaran Kasih Manado lebih dari separuh pada kategori tinggi.

2. Beban kerja mental perawat di IGD dan ICU RSU GMIM Pancaran Kasih Manado umumnya pada kategori sedang.

3. Penerapan patient safety di IGD dan ICU RSU GMIM Pancaran Kasih Manado paling banyak pada kategori kurang.

4. Terdapat hubungan bermakna antara beban kerja fisik perawat dengan penerapan patient safety di IGD dan ICU RSU GMIM Pancaran Kasih Manado.

5. Tidak terdapat hubungan bermakna antara beban kerja mental perawat dengan penerapan patient safety di IGD dan ICU RSU GMIM Pancaran Kasih Manado.

\section{DAFTAR PUSTAKA}

Aprilia, S.(2011). Faktor-faktor yang Mempengaruhi Perawat dalam Penerapan IPSG (International Patient Safety Goal) pada Akreditasi JCI (Joint Commission International) di Instalasi Rawat Inap RS Swasta X. diakses pada 9 Desember 2018

Bawelle, S. C.(2013). Hubungan Pengetahuan dan Sikap Perawat dengan Pelaksanaan Keselamatan Paien (Patient Safety) di Ruang Rawat Inap RSUD Liun Kendage Tahuna. Ejournal keperawatan (eKp) vol. 1 no 1.

Frichilia, C.(2016). Stres Kerja serta Hubungannya dengan Kinerja karyawan berdasarkan Gender (Studi pada Karyawan PT. Bank Danamon, TBK Manado). Jurnal Berkala lmiah Efisiensi vol. 16 No. 04 Tahun 2016.

Gunawati, R.(2013). Analisis Beban Kerja Mental Perawat IGD RSUD Pandan Arang

Boyolali. http://eprints.undip.ac.id/53698/diaks es pada 3 Oktober 2018

Haryanti.(2013). Hubungan antara Beban Kerja dengan Stres Kerja Perawat di Instalasi Gawat Darurat RSUD Kabupaten Semarang. Diakses pada 11 Desember 2018

Haryanto, W. C \& Rosa, E. M.(2016). Pengaruh Beban Kerja dan Kelelahan Perawat terhadap Perawatan Infus di Ruang Perawatan Kelas III RSUD Sukoharjo. Jurnal Meidcoeticolegal dan Manajemen Rumah Sakit.

Kambuaya, P.(2016). Hubungan Beban Kerja Perawat dengan Waktu Tanggap Pelayanan Keperawatan Gawat Darurat Menurut Persepsi Pasien di IGD RSUD Kabupaten Sorong.

https://ejournal.unsrat.ac.id/index.ph $\mathrm{p} / \mathrm{jkp} /$ article/view/11908/11497diaks es pada 20 September 2018

Kamil, H.(2010). Patient Safety. Dalam http://www.jurnal.unsyiah.ac.id/INJ/ article/viewFile/6341/5208diakses pada 16 September 2018

Kumbadewi, L.(2016). Pengaruh Umur, Pengalaman Kerja, Upah, Teknologi dan Lingkungan Kerja terhadap Produktivitas Karyawan. E-Journal Bisma Universitas Ganesha Jurusan Manajemen volume 4.

Lombogia.(2016). Hubungan Perilaku dengan Kemampuan Perawat dalam Melaksanakan Keselamatn Pasien (Patient Safety) di Ruang Akut Instalasi Gawat Darurat RSUP Prof. Dr. R. D.Kandou Manado. Dalam https://ejournal.unsrat.ac.id/index.ph $\mathrm{p} / \mathrm{jkp} / \mathrm{article} / \mathrm{view} / 12916 / 12503$ diaks es pada 3 oktober 2018

Manorek, H.(2018). Faktor-faktor yang Berhubungan dengan Penerapan Sasaran Keselamatan Pasien pada Perawat di Ruang Rawat Inap 
e-journal Keperawatan (e-Kp) Volume 7 Nomor 1, Februari 2019

Rumah Sakit Umum Daerah Dr. Sam Ratulangi

Tondano.

Ejounalhealth.com

Renoningsih, D. P.(2016). Faktor-faktor yang Berhubungan dengan Penerapan Patient Safety pada Perawat di Instalasi Rawat Inap Rumah Sakit Umum Pancaran Kasih GMIM Manado. Ejournalhealth.com.

Satria, W.(2013). Hubungan Beban Kerja dengan Kinerja Perawat dalam Mengimplementasikan Patient Safety di Rumah Sakit Universitas Hasanuddin. Diakses pada 12 Desember 2018

Setiadi.(2013). Konsep dan Praktik Penulisan Riset Keperawatan. Yogyakarta:Graha Ilmu

Sukmaretnawati, C.(2014). Pengaruh Stres Kerja Perawat terhadap Perilaku Implementasi Patient Safety di IGD RS Panembahan Senopati Bantul. Indonesian Journal of Nursing Practices.

Susanto, Bayhakki, \& Arneliwati.(2015).Hubungan

Persepsi Beban Kerja dengan Stres Kerja pada Perawat IGD dan ICU Eka Hospital Pekanbaru. https://jom.unri.ac.id/index.php/JOM PSIK/article/view/5210/5089 diakses pada 26 September 2018

WHO.(2011). Panduan Kurikulum Keselamatan Pasien. Dalam http://apps.who.int/iris/bitstream/han dle/10665/44641/9789241501958 in d.pdf;jsessionid=119DBDA8FB64D 87FFB2B8F00274985D2? sequence $=$ 26diakses pada 16 Oktober 2018 